\title{
Musculoskeletal manifestations of bacterial endocarditis
}

\author{
O. L. MEYERS AND P. J. COMMERFORD
}

From the Rheumatic Diseases Unit, University of Cape Town, and Groote Schuur Hospital, Observatory, 7925, Cape, South Africa

SUMMARY The records of 180 patients out of 247 with bacterial endocarditis were examined. 50 patients had rheumatic manifestations. In 10 there was arthritis of 2-12 weeks' duration before diagnosis; 19 had myalgia/arthralgia; 17 had back or neck pain; 14 had demonstrable arthritis; and 2 tenosynovitis of the foot. Of the 14 patients with arthritis, 8 had monarticular arthritis and 6 polyarticular. All but one patient had a raised erythrocyte sedimentation rate, and in one patient rheumatoid factor was positive. The rheumatic features responded when the endocarditis was treated. Some of the symptoms undoubtedly resulted from the infection and fever of the endocarditis, and emboli may have caused the transient aches but there was no evidence that they caused the synovitis in the patients with arthritis. The rheumatic manifestations of bacterial endocarditis can mimic other rheumatic diseases and disguise the underlying disease.

Bacterial endocarditis presents few diagnostic problems when a fever, cardiac murmur, and embolic phenomena coexist. The capacity to mimic other diseases is, however, well recognized, and the potential for a fatal outcome adds an urgency to the diagnostic problem.

The manifestations of bacterial endocarditis in the musculoskeletal system are not well documented by standard textbooks of medicine (Beeson, 1975) or clinical reviews (Cates and Christie, 1951; Tumulty, 1960; Hayward, 1960, 1973; Hickie, 1961; Lerner and Weinstein, 1966), neither do standard textbooks of rheumatology mention the musculoskeletal manifestations. Huskisson and Hart (1975) give a brief description of the features in their book of rheumatological vignettes, and Huskisson (1974) has drawn attention to the subject after a description of the musculoskeletal features by Deshayes et al. (1974). The paucity of literature suggests that there is a general unfamiliarity with the musculoskeletal manifestations of bacterial endocarditis and their capacity to mimic other rheumatic diseases. We report the features of musculoarticular involvement in 50 patients with bacterial endocarditis.

\section{Materials and methods}

The clinical records in the Department of Medicine

Accepted for publication March 5, 1977

Correspondence to Prof. O. L. Meyers at Groote Schuur Hospital of all patients in whom a diagnosis of bacterial endocarditis was made over a 6-year period (1969-1974) were recalled. The clinical, laboratory, and therapeutic aspects of the case notes were examined, and particular attention was paid to data concerning the musculoskeletal system. Records of a diagnosis of unequivocal bacterial endocarditis were accepted when the classical clinical signs/symptoms were present, or where there was strong evidence for the antibiotic therapy given.

Arthralgia/myalgia was recorded whenever reference had been made to joint or muscle pain without clinically apparent disease. Arthritis was recorded whenever joint swelling was associated with the other signs of inflammation (redness, heat, impaired range of motion). In some instances the isolated finding of joint swelling was accepted as evidence of arthritis if there were no concomitant signs to suggest other rheumatic diseases.

\section{Results}

A diagnosis of bacterial endocarditis was entered on the records of 247 patients. 180 records were available for analysis. In 50 cases $(28 \%)$ rheumatic manifestations were recorded, and these form the basis of our report. There were 27 females and 23 males in this group, ages ranging from 13 to 64 years, mean age $32 \cdot 4$ years. 
PRECEDING ARTHRITIS (10)

In 10 subjects ( 7 female, 3 male) there was a history of preceding arthritis for 2 to 12 weeks before the diagnosis was established. One patient with an acute ankle arthritis was treated for acute gout, and another had an exploration of her sacroiliac joint. The knee and ankle were most commonly affected. In 3 patients a polyarthritis affecting arms and legs was described. Blood cultures were positive in 3 patients, when the diagnosis was finally made.

MYALGIA/ARTHRALGIA (19)

Myalgia/arthralgia was recorded in 19 patients. The symptoms were nonspecific and occurred in patients who had a febrile illness. Symptoms were present at admission, but antedated the diagnosis by 6 weeks in some. In 8 subjects myalgia/arthralgia was the sole rheumatic manifestation.

\section{BACKACHE (17)}

In 17 patients ( 8 male, 9 female) back or neck pain was dominant. In 8 ( 2 males, 6 females) lumbar and loin pain was recorded and all of these had evidence of renal involvement, including one patient with proven renal infarction. All the patients with lumbar and loin pain were febrile. Of another 9 patients (6 male, 3 female), 7 had severe lumbar backache and 2 prominent neck pain. These symptoms frequently antedated the diagnosis by 1-12 weeks and were the main symptoms on admission. All these patients had a fever. One patient, aged 29, had narrowing of the disc space of $L 1 / 2$ and another a transient depression of an ankle jerk. A further patient with severe backache had a suppurative paravertebral abscess at autopsy. Blood cultures were positive in 11 of these patients with backache.

\section{ARTHRITIS (14)}

Fourteen patients (11 males, 3 females), had demonstrable arthritis at the time of admission most commonly affecting the knees (5), the elbows (3), and ankles (3). The shoulder, big toe metatarsophalangeal joint, and hips were affected in two instances each. Most patients had an insidious and subacute arthritis. In 8 patients the arthritis was monarticular, affecting the knees, ankles, and shoulders. In 6 polyarticular arthritis presented in combinations of knee-ankle, knee and shoulder, though 2 patients had affected wrists, metacarpophalangeal and interphalangeal joints, and one metatarsophalangeal joints of the toes.

Synovial fluid of one patient showed a white cell count of $20000 \mathrm{~mm}^{3}\left(20 \cdot 0 \times 10^{9} / 1\right)$, poor mucin clot, and a low total haemolytic complement level. The fluid was sterile on culture. $X$-rays were negative in all cases where they were taken. All but one patien. had raised erythrocyte sedimentation rates, but the white cell count was normal in 7 patients. Rheuma? toid factor measured in 8 patients was positive in $\mathrm{E}$ (latex 1/5200, SCAT 1/16). Antistreptolysin 0 titre measured in 5 patients was normal in 4. In one patient with a titre of 500 Todd units a throat culture failed to show $\beta$ haemolytic streptococci. This patient had classical embolic features of bacteriat endocarditis. The blood culture data in this group showed 10 positive cultures (5 Strep. viridansw 3 Staph. aureus, 1 Staph. albus, and $1 \beta$ haemolytio streptococcus, not group A). Embolic phenomen⿳亠口冋 were present in 11 patients; 7 patients had digita clubbing which was very marked in one patient witi a ventricular septal defect and septic emboli to the lungs. This patient presented with bilateral knes effusions but showed no radiological evidence of periostitis.

\section{TENOSYNOVITIS (2)}

In 2 patients there was pain of the dorsum of the foot, and clinical examination showed a teno $=$ synovitis of the dorsal synovial sac, and preservation $\overrightarrow{9}$ of the pedal pulses. We have seen another patient with bacterial endocarditis who presented wa similar features.

\section{Discussion}

This study has shown that bacterial endocarditis ma manifest as an acute arthritis, a febrile backache tenosynovitis, and arthralgia/myalgia. These rheum atic manifestations may occur as isolated features of in combinations. They bear a temporal relationshis to the infection and respond quickly once the endoe carditis is treated. Noteworthy, too, is the frequenct with which a preceding arthritis occurred before the patients were hospitalized. Such episodes of arthriti? occurred up to 12 weeks before hospitalization.

The importance of these findings lies in theip potential to distract attention from their cause, thus leading to further delays in diagnosis. A low-grade arthritis occurring as part of bacterial endocarditis particularly when the rheumatoid factor is positive (Williams and Kunkel, 1962), or unfamiliarity wit the febrile backache symptom complex, may easily mislead. Bontoux et al. (1967), Holler and Pecorse (1970) and Deshayes et al. (1974) are responsible fó describing arthritis, febrile backache, and myalgia i bacterial endocarditis, which has helped to increase awareness of these problems.

The arthritis, however, remains poorly doculके mented in adults in the English language literature? 
In children on rheumatic fever prophylaxis, attention has been drawn to the frequency with which arthritis, usually monarthritis, occurs when bacterial endocarditis develops (Doyle et al., 1967).

Some of the symptoms, such as arthralgia/ myalgia, are easily understood because they probably result from the infection and accompanying fever. It is also possible that in some patients backache may be a nonspecific manifestation of the infection. Emboli, however, are believed to cause some of the transient aches of which these patients may complain (Hayward, 1960). Renal infarction and a paravertebral abscess in each of 2 patients in our study supports this view. In the patients with arthritis there was no clear evidence to suggest that emboli were the cause of the synovitis, although such a mechanism is possible and likely in some patients. L1/2 disc involvement in the one patient can probably be referred to embolism and resembles the patient described by Bontoux et al. (1967).

Much has been written about the embolic features of infective endocarditis but there is good evidence that immune complexes and not emboli are the cause of some of the 'embolic' features. Thus, the nephritis of endocarditis can be added as a further possible cause of backache, while the finding in one patient of low synovial fluid complement despite an obvious inflammatory synovial fluid suggests that at least some of the arthritis may be explained on an immune complex basis. As far as is known, none of the patients had a septic arthritis. A further cause for the arthritis may be hypertrophic osteoarthropathy. Although $50 \%$ of the patients with arthritis had clubbing of the digits, the fully developed syndrome was not seen in this study.

Drug-related arthritis, such as diuretic precipitated acute gouty arthritis or a serum sickness-like syndrome are further possible causes, but in this study they were not implicated. The organisms encountered in this study were predominantly Strep. viridans and staphylococci and a reactive arthritis to these infective organisms does not seem likely, although in appropriate circumstances other organisms may produce arthritis in this manner.

Finally, there remains the question of concomitant rheumatic fever. In some of the patients no positive blood cultures were obtained and in a few the antistreptolysin 0 titres were raised. None of these patients, however, fulfilled the criteria for acute rheumatic fever. The manifestations of a predominant monarticular arthritis, the lack of flitting arthritis, and the presence of other features associated with bacterial endocarditis makes rheumatic fever less likely. It should be recognized that although rare, the two diseases are known to coexist.

We believe that the rheumatic manifestations of bacterial endocarditis deserve attention because of their variety and potential to mimic other rheumatic diseases, drawing attention away from the serious nature of the underlying cause.

\section{References}

Beeson, P. (1975). Infective endocarditis. Textbook of Medicine, 14th ed., p. 308. Ed. by P. Beeson and W. McDermott. Saunders, Philadelphia.

Bontoux, D., Massias, P., and Forette, B. (1967). Spondylodiscite lombaire en cours d'une endocardite enterocoque. Revue du Rhumatisme, 34, 589-591.

Cates, J. E., and Christie, R. V. (1951). Subacute bacterial endocarditis. Quarterly Journal of Medicine, 20, 93-130.

Deshayes, P., Durand, J. P., Houdent, G., Humbert, G., and Breton, G. (1974). A propos des manifestations rhumatologique des endocarditis bactérieens. Revue du Rhumatisme, 41, 135-139.

Doyle, E. F., Spagnuolo, M., Taranta, A., Kuttner, A. G., and Markowitz, M. (1967). The risk of bacterial endocarditis during antirheumatic prophylaxis. Journal of the American Medical Association, 201, 807-812.

Hayward, G. (1960). Bacterial endocarditis. Proceedings of the Royal Society of Medicine, 53, 551-554.

Hayward, G. (1973). Infective endocarditis: a changing disease. I. British Medical Journal, 2, 706-709.

Hickie, J. B. (1961). Bacterial endocarditis in Sydney, 1950-1959. Medical Journal of Australia, 1, 929-934.

Holler, J. W., and Pecora, J. S. (1970). Backache in bacterial endocarditis. New York State Journal of Medicine, 70, 1903-1905.

Huskisson, E. C. (1974). Arthritis as a sign of another disease. Current Medical Research and Opinion, 2, 510-514.

Huskisson, E. C., and Hart, F. D. (1975). Infective endocarditis. Joint Disease: All the Arthropathies, 2nd ed., p. 56. Wright, Bristol.

Lerner, P. I., and Weinstein, L. (1966). Infective endocarditis in the antibiotic era. New England Journal of Medicine, 274, 259-266.

Tumulty, P. A. (1960). The management of bacterial endocarditis. Archives of Internal Medicine, 105, 126-142.

Williams, R. C., Jr., and Kunkel, H. G. (1962). Rheumatoid factor, complement, and conglutinin aberrations in patients with subacute bacterial endocarditis. Journal of Clinical Investigation, 41, 666-675. 